\title{
ANALISIS KEMAMPUAN OPEN SPIKE PADA SISWA PUTRA EKSTRAKURIKULER BOLA VOLI DI SMPN 18 KOTA BENGKULU
}

\author{
Heru Herianto \\ Universitas Bengkulu \\ heruherianto45@gmail.com \\ Yarmani \\ Universitas Bengkulu \\ Ari Sutisyana \\ Universitas Bengkulu
}

\begin{abstract}
Abstrak
Penelitian ini bertujuan untuk mengetahui analisis kemampuan open spike pada siswa putra ekstrakurikuler bola voli di SMPN 18 kota Bengkulu. Penelitian ini merupakan penelitian deskriptif kuantitatif. Dalam penelitian ini yang menjadi populasi adalah seluruh siswa ekstrakurikuler bola voli SMPN 18 Kota Bengkulu yang berjumlah 30 orang siswa putra. Pada penelitian ini sampelnya sebanyak 30 siswa yang mengikuti ekstrakurikuler bola voli di SMP N 18 Kota Bengkulu, Instrumen dalam penelitian ini dibuat atau dimodifikasi untuk mengukur kemampuan siswa secara individu bukan beregu, analisis data yang digunakan menggunakan deskriptif kuantitatif dengan persentase. Hasil penelitian menunjukan bahwa analisis kemampuan open spike pada siswa putra ekstrakurikuler bola voli di SMPN 18 Kota Bengkulu berada pada kategori sangat baik 0 , kategori baik 2 orang siswa atau 6,66\%, kategori cukup sebanyak 4 orang siswa atau 13,33\%, katagori sedang sebanyak 4 orang siswa atau $13,33 \%$, kategori kurang sebanyak 10 orang siswa atau 33,33\%, dan kategori sangat kurang sebanyak 10 orang siswa atau 33,33\%. Berdasarkan nilai ratarata, yaitu, 16,03 hasil penilaian analisis kemampuan open spike pada siswa putra ekstrakurikuler bola voli di SMPN 18 Kota Bengkulu berada pada kategori kurang.
\end{abstract}

Kata kunci: open spike, bola voli dan ektrakurikuler

\begin{abstract}
The research aims to know analysis ability open spike in son student extracurricular volley ball in SMPN 18 bengkulu city. The research is descriptive quantitative. On this research the population is all student extracurricular volley ball SMPN 18 bengkulu city numbered threety people son student. On this research sample numbered 30 which follow extracurricular volley ball in SMPN 18 Bengkulu city, instrument on research created on individual not a team. Analysis of data used descriptive quantitative with a percentage. The result of research showed that anaylis open spike on son student extracurricular volle ball in SMPN 18 Bengkulu city is very good category 0 , good category 2 people student or 6,6\%, enough category 4 people student or 13,33\%, medium category 4 people student or 13,33\%, less category 10 people student or $33,33 \%$ and very less category 10 people student or 33,33\%. Based on value rating is 16,03 result of research Analysis ability open spike on son's student extracurricular volley ball in SMPN 18 Bengkulucity at in the less category.
\end{abstract}

Keywords: Open spike, volley ball and extracuriculer 


\section{PENDAHULUAN}

Indonesia merupakan salah satu dari sekian banyak negara-negara di dunia yang sedang giatnya melaksanakan pembangunan disegala bidang-bidang, maka seharusnya pembangunan diarahkan pada peningkatan kualitas manusia, sehingga terbentuknya manusia Indonesia yang terampil, cerdas, berkepribadian serta sehat jasmani dan rohani guna pembangunan bangsa. Pembangunan dibidang olahraga merupakan salah satu aspek pembangunan yang tidak kalah pentingya di bandingkan dengan aspek lainya.

Permainan bola voli selalu memiliki karakter pertandingan oleh karena itu setiap pemain di tuntut untuk berusaha semaksimal mungkin. Elemen-elemen permainan secara proporsional mudah di pelajari, karena dalam waktu yang singkat sudah dapat di peroleh hasilnya.

Menurut Amung Ma'mun, dkk (2001:43) Dalam permainan bola voli ada beberapa bentuk tehnik dasar yang harus dikuasai. Setiap pemain pasti ingin mempunyai prestasi yang tinggi dalam bermain bola voli,dengan itu pemain perlu meningkatkan prestasi permainan bola voli. Pengembangan potensi peserta didik sebagai mana di maksud dalam tujuan pendidikan nasional tersebut dapat di wujudkan melalui kegiatan ekstrakurikuler yang merupakan salah satu kegiatan dalam program kurikuler. Berdasarkan hasil pengamatan saat tes pada kegiatan magang tiga pada kegiatan ekstrakurikuler SMPN 18 Kota Bengkulu masih banyak mengalami kendala dalam melakukan tehnik dasar permainan bola voli.

Dari pengamatan peneliti saat melakukan maganag tiga peneliti melihat proses siswa latihan, di sini peneliti melihat langsung kurangnya pemahaman pada open spike. Berdasarkan latar belakang di atas, maka peneliti tertarik untuk melakukan penelitian dengan judul "Analisis Kemampuan Open Spike Pada Siswa Putra

\section{Ekstrakurikuler Bola Voli Di SMPN 18 Kota Bengkulu".}

Rumusan masalah yaitu: Bagaimanakah kemampuan open spike dalam latihan pada ekstrakurikuler bola voli SMPN 18 Kota Bengkulu. Menurut Soenardi (2003:24) Kemampuan (ability) seseorang akan turut serta menentukan perilaku dan hasilnya. Yang dimaksud kemampuan atau ability ialah bakat yang melekat pada seseorang untuk melakukan suatu kegiatan secara fisik atau mental yang ia peroleh sejak lahir, belajar, dan dari pengalaman.

Berdasarkan pengertian-pengertian tersebut, dapat di simpulkan kemampuan (ability) adalah kecakapan atau potensi menguasai yang merupakan bawaan sejak lahir atau merupakan hasil latihan yang digunakan untuk mengerjakan sesuatu yang diwujudkan melalu tes.

Menurut Gunter Blume (2004:2) Permainan bola voli adalah suatu permainan untuk waktu senggang dan pertandingan. Permainan bola voli merupakan suatu permainan regu yang sangat menarik dan termasuk ke dalam kelompok permainan menyerang dan bertahan. Permainan bola voli mempunyai karakter-karakter tertentu dan di mainkan oleh dua regu yang berlawanan. Secara sederhana teknik dapat diartikan sebagai cara.

Menurut Thiess et al dalam Syafruddin (2011:125) Teknik adalah cara khusus yang dapat dilakukan atau direalisasikan untuk memecahkan suatu tugas gerakan olahraga dalam praktek bardasarkan kondisi manusia secara utuh.

Teknik memukul spike bola dalam permainan bola voli adalah bagaimana cara seseorang atau atlet bola voli memukul bola dengan keras dan terarah ke daerah pertahanan lawan. Menurut Amung Ma'mun, dkk (2001:65) Spike merupakan salah satu bentuk serangan dalam permainan bola voli. Karakteristik bola hasil spike adalah menukik, tajam, dan cepat. Hakikat ekstrakurikuler Menurut Kompri (2016:223) Kegiatan 
ekstrakurikuler adalah program kurikuler yang alokasi waktunya tidak ditetapkan dalam kurikuler.

\section{METODE}

Penelitian ini adalah usaha dalam melakukan segala sesuatu untuk mengisi kekosongan atau kekurangan yang ada, menggali lebih dalam apa yang telah ada, Penelitian ini merupakan penelitian deskriptif kuantitatif yang mengambarkan situasi atau keadaan yang sedang berlangsung dengan melakukan tes.

Penelitian deskriptif merupakan jenis penelitian untuk memberi uraian mengenai fenomena atau gejala sosial yang diteliti dengan mendeskripsikan tentang nilai variabel mandiri, baik satu variabel atau lebih (independent) berdasarkan indikatorindikator dari variabel yang diteliti tanpa membuat perbandingan atau menghubungkan antara variabel yang diteliti guna untuk eksplorasi dan klasifikasi dengan mendeskrifsikan sejumlah variabel yang berkenaan dengan masalah variabel yang diteliti Iskandar (2010:61). Tempat penelitian ini dilakukan dilapangan SMPN 18 Kota Bengkulu.

Dilaksanakan selama 1 bulan terhitung sejak tanggal 10 April - 5 Mei 2018. Menurut Dewi Laelatul Badriah (2006:80). Dalam penelitian ini yang menjadi populasi adalah seluruh siswa ekstrakurikuler bola voli SMPN 18 Kota Bengkulu yang berjumlah 30 orang siswa putra. Sampelnya sebanyak 30 siswa yang mengikuti ekstrakurikuler bola voli di SMPN 18 Kota Bengkulu.

Instrumen dalam penelitian ini dibuat atau dimodifikasi untuk mengukur kemampuan siswa secara individu bukan beregu. Tes yang dilakukan adalah tes ketepatan (spike) yaitu tes memukul bola dengan mengarahkan bola ketempat-tempat yang telah di beri nilai atau skor.Tujuan tes open spike untuk mengetahui kemampuan peserta tes dalam melakukan open spike secara baik.
1. Alat-alat yang digunakan untuk mengukur kemampuan open spike, sebagai berikut: lapangan, bola voli, net, catatan, pluit.

2.Pelaksanaan tes

a. Sebelum melakukan tes, alat dipersilakan untuk melakukan percobaan smash sebanyak 2 kali.

b. Siswa melakukan smash sebanyak 10 kali.

c. Siswa melakukan smash dengan cara melempar bola sendiri.

d. Posisi untuk melakukan smash di tengah (posisi 3).

e. Net di modifikasi.

3. Penilaian

a. Penilaian sesuai dengan jatuhnya bola di daerah sasaran.

b. Bola menyangkut di net dan keluar lapangan (out) diberinilai 0 .

c. Nilai yang diperoleh adalah skor total dari 10 kali smash yang dilakukan.

Tabel 1. Norma Tes Ketepatan Spike

\begin{tabular}{c|c|c}
\hline NO & Kriteria & Skor \\
\hline 1 & Sangat baik & $>33$ \\
\hline 2 & Baik & $28-32$ \\
\hline 3 & Cukup & $23-27$ \\
\hline 4 & Sedang & $18-22$ \\
\hline 5 & Kurang & $13-17$ \\
\hline 6 & Sangat Kurang & $<12$
\end{tabular}

Sumber :Uji instrumen

Teknik analisis data, teknik analisis data yang digunakan dalam penelitian ini adalah analisis deskriptif kuantitatif, analisis data yang digunakan menggunakan deskriptif kuantitatif dengan persentase.

HASIL DAN PEMBAHASAN

Tabel 2. Rekapitulasi Hasil Pengamatan Aktifitas Siswa

\begin{tabular}{c|c|c|c|c|c|c}
\hline \multirow{2}{*}{ No } & Aspek & \multicolumn{4}{|c|}{ Aktifitas Siswa } & Ket \\
\cline { 2 - 7 } & $\begin{array}{c}\text { yang } \\
\text { diamati }\end{array}$ & Ya & $\%$ & tidak & $\%$ & \\
\hline Kedisiplinan (I) & & & & & \\
\hline
\end{tabular}




\begin{tabular}{|c|c|c|c|c|c|}
\hline 1 & $\begin{array}{l}\text { Siswa } \\
\text { sering } \\
\text { terlambat }\end{array}$ & 9 & 30 & 21 & 70 \\
\hline 2 & \begin{tabular}{|l|} 
Siswa \\
melakukan \\
pemanasan \\
mandiri \\
\end{tabular} & 26 & 86,6 & 4 & 3,3 \\
\hline 3 & \begin{tabular}{|l} 
Siswa \\
memperhat \\
ikan \\
pelatih \\
\end{tabular} & 27 & 90 & 3 & 10 \\
\hline & Jumlah & 62 & 206.6 & 28 & 3.3 \\
\hline & ta rata & 20,66 & 68,8 & 9,33 & 31,1 \\
\hline & $\begin{array}{l}\text { la Gerak } \\
\text { sar(II)] }\end{array}$ & & & & \\
\hline 4 & $\begin{array}{l}\text { Posisi } \\
\text { tubuh } \\
\text { sempurna }\end{array}$ & 17 & 56,6 & 13 & 43, \\
\hline 5 & $\begin{array}{l}\text { Posisi kaki } \\
\text { pada saat } \\
\text { melompat } \\
\text { sempurna }\end{array}$ & 19 & 63,3 & 11 & 36, \\
\hline 6 & $\begin{array}{l}\text { Lompatan } \\
\text { seimbang }\end{array}$ & 24 & 80 & 6 & 20 \\
\hline 7 & $\begin{array}{l}\text { Dorongan } \\
\text { lengan } \\
\text { terlihat } \\
\end{array}$ & 16 & 53,3 & 14 & 46, \\
\hline 8 & $\begin{array}{l}\text { posisi } \\
\text { badan pada } \\
\text { saat lompat } \\
\text { kurang } \\
\text { sempurna }\end{array}$ & 13 & 43,3 & 17 & 56, \\
\hline 9 & $\begin{array}{l}\text { Pukulan } \\
\text { lengan } \\
\text { keras }\end{array}$ & 18 & 60 & 12 & 40 \\
\hline$\overline{10}$ & $\begin{array}{l}\text { Mendarat } \\
\text { tidak } \\
\text { sempurna }\end{array}$ & 19 & 63,3 & 11 & 36,6 \\
\hline \multicolumn{2}{|c|}{ Jumlah } & 126 & 419,9 & 84 & 279 \\
\hline \multicolumn{2}{|c|}{ Rata rata } & 18 & 59,9 & 12 & 39,9 \\
\hline \multicolumn{2}{|c|}{ Nilai tertinggi } & 24 & & 17 & \\
\hline \multicolumn{2}{|c|}{ Terendah } & 13 & & 6 & \\
\hline
\end{tabular}

Dari hasil tes yang telah dilaksanakan dengan 10 kali kesempatan masing masing siswa, diketahui jumlah nilai 481, dengan nilai rata rata 16,03 , dengan nilai tertinggi 28 , dan nilai terendah nilai 7 , selanjutnya dapat dilihat sebaran hasil penelitan tentang analisis kemampuan siswa dalam open spike dalam permainan bola voli siswa Sekolah Menengah Pertama Negeri 18 Kota Bengkulu.

Tabel 3. Hasil Analisis Kemampuan Open Spike Siswa SMPN 18 Kota Bengkulu

\begin{tabular}{c|c|c|c}
\hline No & $\begin{array}{c}\text { Jumlah } \\
\text { Siswa }\end{array}$ & Kriteria & $\begin{array}{c}\% \\
\text { Tase }\end{array}$ \\
\hline 1 & 0 & Sangat Baik & 0 \\
\hline 2 & 2 & Baik & 6,66 \\
\hline 3 & 4 & Cukup & 13,33 \\
\hline 4 & 4 & Sedang & 13,33 \\
\hline 5 & 10 & Kurang & 33,33 \\
\hline 6 & 10 & Sangat kurang & 33,33 \\
\hline \multicolumn{2}{|c|}{30} & Jumlah & $100 \%$ \\
\hline
\end{tabular}

Berdasarkan hasil analisis kemampuan open spike maka dapat di simpulkan bahwa dari tes kemampuan open spike siswa ekstrakurikuler bola voli SMPN 18 Kota Bengkulu yang memiliki kategori paling dominan yaitu terletak pada kategori kurang dan sangat kurang sebanyak 10 orang siswa $(33,33 \%)$, yang kategori cukup dan sedang sebanyak 4 orang siswa $(13,33 \%)$, lalu yang kategori baik sebanyak 2 orang siswa $(6,66 \%)$ dan kategori sangat baik 0 .

\section{PEMBAHASAN}

Berdasarkan hasil penelitian yang diperoleh bahwa pembahasan mengenai Analisis Kemampuan Open Spike Pada Siswa Putra ekstrakurikuler bola voli di SMPN 18 Kota Bengkulu adalah sebagai berikut:

Hasil pengamatan pada Siswa ekstrakurikuler bola voli Sekolah Menengah Pertama Negeri 18 Kota Bengkulu.

1. Siswa sering terlambat sebanyak $=9$ orang siswa atau $30 \%$, yang tepat waktu sebanyak 21 orang siswa atau $70 \%$.

2. Berdasarkan hasil pengamatan diatas diketahui siswa ekstrakurikuler bola voli Sekolah Menengah Pertama Negeri 18 Kota Bengkulu yang Siswa melakukam pemanasan mandiri sebanyak $=26$ orang siswa atau $86,6 \%$, dan yang tidak 
melakukam pemanasan mandiri sebanyak 4 orang siswa atau 13,3\%.

3. Berdasarkan hasil pengamatan diatas diketahui siswa ekstrakurikuler bola voli Sekolah Menengah Pertama Negeri 18 Kota Bengkulu yang Siswa memperhatikan pelatih sebanyak $=27$ orang siswa atau 90\%, dan yang tidak siswa memperhatikan pelatih sebanyak 3 orang siswa atau $10 \%$.

4. Berdasarkan hasil pengamatan diatas diketahui siswa ekstrakurikuler bola voli Sekolah Menengah Pertama Negeri 18 Kota Bengkulu. Posisi tubuh sempurna sebanyak= 17 orang siswa atau $56,6 \%$, dan tidak sempurna sebanyak 13 orang siswa atau $43,3 \%$.

5. Berdasarkan hasil pengamatan diatas diketahui siswa ekstrakurikuler bola voli Sekolah Menengah Pertama Negeri 18 Kota Bengkulu. Posisi kaki pada saat melompat sempurna sebanyak $=19$ orang siswa atau 63,3\%, dan tidak sempurna sebanyak sebanyak 11 orang siswa atau $36,6 \%$.

6. Berdasarkan hasil pengamatan diatas diketahui siswa ekstrakurikuler bola voli Sekolah Menengah Pertama Negeri 18 Kota Bengkulu. Lompatan seimbang sebanyak $=24$ orang siswa atau $80 \%$, dan Lompatan tidak seimbang sebanyak 6 orang siswa atau $20 \%$.

7. Berdasarkan hasil pengamatan diatas diketahui siswa ektrakurikuler bola voli Sekolah Menengah Pertama Negeri 18 Kota Bengkulu. Dorongan lengan terlihat sebanyak = 16 orang siwa atau 53,3\%, dan Dorongan lengan tidak terlihat sebanyak 14 orang siswa atau $46,6 \%$.

8. Berdasarkan hasil pengamatan diatas diketahui siswa ekstrakurikuler bola voli Sekolah Menengah Pertama Negeri 18 Kota Bengkulu. posisi badan pada saat lompat sempurna sebanyak = 13 orang siswa atau $43,3 \%$, dan posisi badan pada saat lompat kurang sempurna sebanyak 17 orang siswa atau $56,6 \%$.
9. Berdasarkan hasil pengamatan diatas diketahui siswa ekstrakurikuler bola voli Sekolah Menengah Pertama Negeri 18 Kota Bengkulu. Pukulan lengan keras sebanyak = 18 orang siswa atau $60 \%$, dan Pukulan lengan tidak keras sebanyak 12 orang siswa atau $40 \%$.

10. Berdasarkan hasil pengamatan diatas diketahui Siswa ekstrakurikuler bola voli Sekolah Menengah Pertama Negeri 18 Kota Bengkulu. Mendarat tidak sempurna sebanyak = 19 orang siswa atau 63,3\%, dan Mendarat sempurna sebanyak 11 orang siswa atau $36,60 \%$.

Jadi, hasil dari 30 orang siswa yang mengikuti kegiatan ekstrakurikuler, permainan bola voli dari hasil observasi dengan 10 item yang diamati dan dikelompokan kedalam 2 indikator 1). Kedisiplinan yaitu 21 orang siswa atau $70 \%$ baik dan 9 orang siswa kurang disiplin atau 30 \%. 2 ). Pola Gerak Dasar smash baik berjumlah 18 orang siswa atau 60\% sedangkan pada aspek dalam Pola gerak dasar smash belum baik sebanyak 12 orang siswa atau $40 \%$.

\section{PENUTUP}

\section{Simpulan}

Penelitian ini bertujuan untuk mengetahui kemampuan open spike siswa putra ekstrakurikuler bola voli di SMPN 18 Kota Bengkulu. Berdasarkan hasil tes kemampuan open spike yang diikuti oleh 30 siswa dapat diketahui yaitu kategori sangat baik 0 kategori baik 2 orang siswa atau 6,66\%, katagori cukup sebanyak 4 orang siswa atau $13,33 \%$, kategori sedang sebanyak 4 orang siswa atau $13,33 \%$, kategori kurang sebanyak 10 orang siswa atau 33,33\%, dan kategori sangat kurang sebanyak 10 orang siswa atau $33,33 \%$. Pada penelitian ini diketahui yang paling dominan yaitu berada pada kategori kurang.

\section{Saran}

Sehubungan dengan simpulan yang telah diambil, maka kepada para pembina, pelatih dan pihak sekolah khususnya untuk 
kegiatan ekstrakurikuler bola voli di Sekolah Menegah Pertama Negeri 18 Kota Bengkulu. Disarankan untuk melakukan langkahlangkah sebagai berikut:

1. Kepada Pembina dan Pelatih, perlu mengambil suatu langkah pembinaan keseluruhan terhadap siswanya, agar siswa tetap berlatih secara terusmenerus dan hendaknya menambah porsi pada kedisiplinan dalam latihan sehingga keaktifan siswa dalam latihan meningkat karena pembinaan yang baik itu adalah pembinaan yang terus menerus untuk mencapai prestasi yang maksimal.

2. Kepada pihak sekolah minta dapat memfasilitasi pembinaan ekstrakurikuler di SMPN 18 Kota Bengkulu.

3. Kepada siswa harus disiplin, selalu belajar dan berlatih dengan sungguhsungguh agar dapat mencapai prestasi yang maksimal.

4. Kepada Program Studi S-1 Penjas Universitas Bengkulu hendaknya bekerjasama dengan pihak terkait seperti KONI, DISPORA dan PBVSI dan pihak Sekolah untuk membangkitkan kembali permainan bola voli dengan lebih banyak mengadakan event untuk tingkat Sekolah, sehingga dalam penerapan pembinaan ini memiliki target untuk berprestasi.

5. Kepada orang tua siswa untuk senantiasa memberikan motivasi dan respon yang baik terhadap penerapan pembinaan permainan bola voli di tingkat persekolahan khususnya Sekolah Menengah.

6. Kepada peneliti selanjutnya untuk lebih terarah dan lebih tertuju pada penelitian.

\section{DAFTAR PUSTAKA}

Badriah, Laelatul, Dewi. (2006). Metode Penelitian IImu-IImu Kesehatan. Bandung: MULTAZAM.
Blume, Gunter. (2004). Permainan Bola Voli (Training-Teknik-Taktik). Padang: FIK UNP,

Fauzi. (2011). Penyusunan Baterry Test Olahraga Bola Voli. Yogyakarta: Universitas Negeri Yogyakarta.

Iskandar. (2008). Metodologi Penelitian Pendidikan dan Sosial (Kuantitatif dan Kualitatif). Jakarta: Gaung Persada Press (Press).

Kompri. (2016). Manajemen Pendidikan. Yogyakarta: AR- RUZZ MEDIA.

MA'mun, Amung. (2011). Pendekatan Keterampilan Taktis dalam Pembelajaran Bola Voli. Jakarta: Direktorat Jenderal Olahraga.

Sunardi, dkk. (2013). Bola Voli. Surakarta: UNS Press.

Syafruddin. (2011). IImu Kepelatihan Olahraga Teori dan Aflikasinya dalam Pembinaan Olahraga. Padang: UNP Press.

Soenardi. (2003). Pengertian Kemampuan (Ability) Menurut Para Ahli. http://infodanpengertian.blogspot.co.id 2015/04/penertian-kemampuanability-menurut.htm|?m=1 (diakses hari senin tanggal 5 maret jam 11:23 2018) 